\title{
Educare - Investigando a efetividade do uso de objetos de aprendizagem em cursos preparatórios para processos seletivos
}

\author{
Pedro Mietlicki, Calebe Conceição, Glederson Lessa dos Santos, Carla de Aquino \\ ${ }^{1}$ Instituto Federal Sul Rio-Grandense (IFSUL), Campus Charqueadas \\ Rua Gal. Balbão, 81, Charqueadas - RS, Brasil - CEP 96745-000 \\ pedromietlicke@gmail.com, \\ \{calebeconceicao,gledersons,carladeaquino\}@ charqueadas.ifsul.edu.br
}

\begin{abstract}
The use of Learning Objects (OAs) in teaching and learning processes has been widely advocated in literature, and this work aims to quantify their effectiveness in the context of preparation for entrance exams. The unique characteristics of this type of exam demand a more directed teaching process and, therefore, conducive to a quantitative investigation. Thus, the Educare web system was developed to support the proposed research, using as a case study the Portuguese language subject of the selective admission process for the integrated technical courses from campus Charqueadas of IFSUL.
\end{abstract}

Resumo. O uso de Objetos de Aprendizagem (OAs) no processo de ensino e aprendizagem tem sido amplamente defendido na literatura, e este trabalho visa quantificar sua efetividade no contexto da preparação para processos seletivos. As características singulares desse tipo de prova demandam um processo de ensino mais direcionado e, portanto, propício à uma investigação quantitativa. Desse modo, o sistema web Educare foi desenvolvido para dar suporte à investigação proposta, utilizando como estudo de caso a disciplina de língua portuguesa do processo seletivo de ingresso para os cursos técnicos integrados do campus Charqueadas do IFSUL.

\section{Introdução}

Os denominados “Objetos de aprendizagem" (OAs) são recursos complementares ao processo de ensino-aprendizagem que podem ser reutilizados em diferentes práticas pedagógicas, o que torna necessário que cada OA seja construído de forma a representar uma unidade mínima de aprendizagem a fim de aumentar a sua reusabilidade.

Ao se considerar o treinamento para participação em processos seletivos, particularidades emergem e balizam consideravelmente os objetivos do ensino, fornecendo um contexto de ensino menos complexo que o contexto tradicional. Os processos seletivos possuem regras específicas definidas em edital, a exemplo do conteúdo programático mais restrito, o método avaliativo normalmente constitui-se de provas escritas, com estilos previsíveis de questões, cujo caráter objetivo permite uma avaliação precisa do desempenho do candidato, livre de subjetivações na correção. Além disso, esses treinamentos tem como meta clara a aprovação - em contraste com a formação para conscientização e emancipação cidadã, defendida por Paulo Freire para a escola tradicional. Essas particularidades pragmáticas facilitam a medição de desempenho e a comparação com os dados 
estatísticos históricos, configurando-se assim um ambiente mais propício à aplicação e à avaliação da efetividade do uso de OAs para atingir a meta de aprovação.

Desse modo, esse trabalho busca investigar características e técnicas de recomendação de Objetos de Aprendizado sob demanda no contexto do treinamento para aprovação em processos seletivos. O sistema de recomendação encontra-se integrado à ferramenta web desenvolvida para dar suporte a esse projeto de pesquisa, com o objetivo de construir automaticamente o itinerário de aprofundamento de estudos de maneira personalizada, tendo como base as características de interação do aluno com o sistema e simulados realizados na plataforma. Para tanto, serão utilizados como estudo de caso os conteúdos de Língua Portuguesa do processo seletivo para ingresso nos cursos técnicos integrado do campus Charqueadas do IFSUL. São reportados nesse trabalho os resultados dos estudos iniciais visando responder à seguinte questão, na direção de aprimorar as recomendações de Objetos de Aprendizagem: os OAs indicados pelo estudante como os mais atrativos são de fato os mais efetivos para o aprendizado?

\section{Referencial teórico e trabalhos relacionados}

Diversos trabalhos na literatura advogam que o uso de OAs qualificam o processo de ensino, permitindo que os alunos se tornem protagonistas de seu aprendizado [Tarouco 2008]. O uso de OAs também é potencialmente benéfico ao ensino de línguas mas, como é apontado por Vilson Leffa, apesar da existência de repositórios públicos e vastos de Objetos de Aprendizagem que dão a impressão de facilidade de acesso a esses recursos, ainda há uma carência de uma oferta mais agilizada e direcionada às demandas identificadas [Leffa 2006].

Ana Bulegon e Eunice Mussoi classificam OAs quanto ao tipo de aprendizagem, de 4 diferentes modos: humanista, baseado nas ideias de Paulo Freire; cognitivista, baseado nas ideias de Jean Piajet; comportamentalista, baseado nas ideias de Burrhus Skinner; e construtivista, baseado nas ideias de David Jonassen [Bulegon and Mussoi 2014]. Todos eles possuem ideias distintas de como ocorre esse processo de aprendizagem. Essas dimensões do aprendizado serão utilizadas como base para identificar o enfoque mais adequado ao aprendizado do indivíduo usuário do sistema de recomendação aqui proposto.

O sistema aqui proposto não é o único que se propõe a ser um ambiente virtual de aprendizagem que faz uso de OAs. No Brasil, existe a Rede Interativa Virtual de Educação (RIVED), um programa da Secretaria de Educação a Distância - SEED, que tem por objetivo a produção de conteúdos pedagógicos digitais, na forma de objetos de aprendizagem [Nascimento 2005]. O projeto desenvolve módulos educativos apoiados em OA para serem integrados no currículo do ensino médio, de modo a ampliar as ferramentas de ensino-aprendizagem disponíveis para professores e alunos. Além disso, pode-se citar os módulos distintos da plataforma Moodle 11 para disponibilização de OAs e realização de simulados, e observar que os Objetos de Aprendizagem estão sendo amplamente utilizados em ferramentas diversas voltadas para o ENEM, os quais possuem abrangência geográfica e de público muito maiores que a do estudo de caso aqui proposto.

\footnotetext{
${ }^{1}$ Disponível em: https://moodle.org/
} 


\section{Desenvolvimento}

O projeto de pesquisa Educare aqui descrito foi dividido em três etapas principais, e possui o sistema web homônimo como plataforma de experimentação e produto final. A primeira etapa contempla a seleção/desenvolvimento de OAs adequados a cada um dos tópicos do conteúdo programático da disciplina de língua portuguesa do curso preparatório. A segunda consiste no desenvolvimento do sistema que irá disponibilizar os OAs para acesso dos alunos voluntários. A última etapa, na qual encontra-se o desenvolvimento do sistema, consiste na coleta, compilação e avaliação dos dados de aplicação da técnica.

O sistema web Educare foi desenvolvido para o cadastro de alunos voluntários, disponibilização de conteúdos e acompanhamento da utilização dos OAs. Foi desenvolvido em HTML5 com layout adaptável (responsivo) à tela de dispositivos móveis, utilizando o framework Bootstrap; foi modelado com Orientação a Objetos em PHP através do framework CodeIgniter que emprega a arquitetura MVC (Model-View-Controller); e usa a base de dados MySQL para armazenamento de dados.

\section{Metodologia}

Foram selecionadas 20 questões extraídas de provas anteriores do processo seletivo de ingresso nos cursos técnicos integrados do IF, e classificadas pelo conteúdo que aborda. Apenas questões dessa origem compõem o banco do sistema. Para cada questão, foram selecionados OAs representativos de cada tipo de enfoque de ensino: humanístico, construtivista, cognitivista, comportamentalista. Na Figura 1 são apresentados quatro exemplos desses OAs, um de cada tipo. A aplicação do teste foi supervisionada, e as questões foram apresentadas uma a uma ao aluno voluntário.

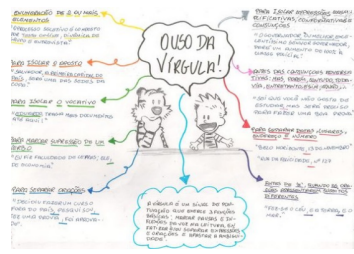

a)

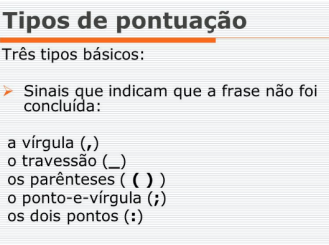

b)

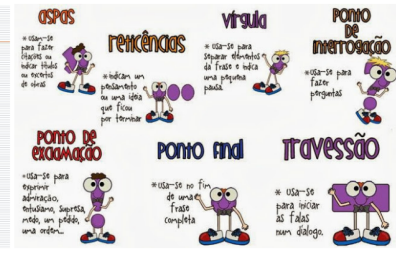

c)

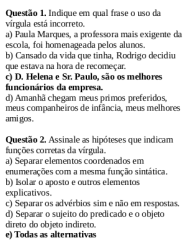

d)

Figura 1. Exemplos de OAs sobre pontuação. a) Cognitivista; b) Construtivista; c) humanista; d) Comportamentalista

O teste foi divido em duas etapas. No primeiro momento, para as primeiras 4 questões, um OA de cada tipo foi apresentado sequencialmente antes do aluno voluntário responder à questão. Além de marcar a resposta, o voluntário deveria escolher o OA que julgou mais atrativo. Em um segundo momento, apenas um OA foi apresentado para cada uma das demais 16 questões, de maneira que cada tipo de enfoque de ensino foi coberto em exatas quatro questões em ordem aleatória. Em todas as etapas, foi dado um tempo constante de exposição à questão juntamente com seus respectivos OAs selecionados (quatro OAs no primeiro momento, um OA no segundo momento).

\section{Resultados}

O teste aplicado contou com a participação de 58 alunos do 1o. ano do ensino médio integrado do IF, recém ingressantes. A escolha desse grupo se deu por questões de praticidade de aplicação. Dadas as limitações de tempo, para cada questão, os alunos voluntários foram expostos ao enunciado e ao(s) seu(s) respectivo(s) OA(s) por um tempo 
de 120 segundos. Ao final, as respostas de todos os testes foram corrigidas, compiladas, e os resultados percentuais de desempenho encontram-se sumarizados na Tabela 1 .

Tabela 1. Percentual de acerto das questões por tipo de OA apresentado.

\begin{tabular}{|c|c|c|}
\hline & Atratividade & Efetividade \\
\hline Humanismo & $\mathbf{4 0 , 2 8 \%}$ & $\underline{32,69 \%}$ \\
\hline Construtivismo & $16,59 \%$ & $57,14 \%$ \\
\hline Comportamentalismo & $\underline{7,58 \%}$ & $41,82 \%$ \\
\hline Cognitivismo & $35,55 \%$ & $\mathbf{7 5 , 4 7 \%}$ \\
\hline Os 4 tipos juntos & - & $46,98 \%$ \\
\hline
\end{tabular}

O tipo de OA considerado mais atrativo pelos voluntários foi o do tipo humanista. Por outro lado, as questões para as quais esse tipo de OA foi apresentado foram a de menor percentual de acerto, o que nos leva a concluir que, resguardadas as influências já mencionadas, não há uma relação direta entre atratividade e efetividade dos OAs. O tipo OA para o qual suas questões tiveram uma maior percentual de acerto foi o tipo cognitivista. Para este, como também para o tipo de OA construtivista, observou-se um percentual de acerto ainda maior que o obtido quando utilizando-se dos 4 tipos de objetos de aprendizagem.

\section{Conclusões}

Claramente, as análises aqui apresentadas servem como diretrizes gerais, mas não valem como regra de aplicação individual. Não se pode assumir, por exemplo, que OAs cognitivos são os mais adequados, e recomendar apenas OAs desse tipo. O sistema de recomendação que pretende-se construir deve, portanto, de maneira automática e contextualizada, realizar análises mais individualizadas para recomendar OAs adequados ao perfil do aluno. Todavia, já é possível afirmar que o tipo de OA ao qual o aluno atribuiu melhor avaliação não é, de fato, o mais efetivo. Como trabalho futuro, serão feitos estudos individualizados com alguns alunos voluntários de maneira a buscar um melhor equilíbrio entre o interesse declarado do aluno e o identificado pelo sistema ao recomendar um OA.

\section{Referências}

Bulegon, A. M. and Mussoi, E. M. (2014). Pressupostos pedagógicos de objetos de aprendizagem. In Objetos de Aprendizagem: teoria e práitca., pages 54-75. Ed. Evangraf, Porto Alegre.

Leffa, V. J. (2006). Nem tudo o que balança cai: objetos de aprendizagem no ensino de línguas. In Polifonia, volume 12. Programa de Pós-Graduação em Estudos de Linguagem (PPGEL), do Instituto de Linguagens /Universidade Federal de Mato Grosso, 2 ed. edition.

Nascimento, A. C. d. A. (2005). Construindo comunidades de elaboradores de objetos de aprendizagem através de conteúdo, tutoria e interação dos pares. Disponível em: http://www.rived.mec.gov.br/artigos/Anna20063.pdf. Acesso em: Jun 2018.

Tarouco, M. L. P. F. . L. M. R. (2008). Diferentes tipos de objetos para dar suporte à aprendizagem. In Novas Tecnologias na Educação, volume 6. RENOTE, 2 ed. edition. 